EL CONTROL DE LAS DISPOSICIONES NORMATIVAS GUBERNAMENTALES CON RANGO DE LEY

SANTIAGO SANCHEZ

UNED 

Revista de Derecho Político, núm. 23, 1986, pp. 169-179

\title{
EL CONTROL DE LAS DISPOSICIONES. NORMATIVAS GUBERNAMENTALES CON RANGO DE LEY *
}

\author{
POR \\ SANTIAGO SANCHEZ \\ UNED
}

"El lenguaje político ordinario es mendaz, pues constituye menos un medio de expresión del pensamiento que un medio de encubrir o impedir dicho pensamiento. Existe un vinculo privilegiado entre la política y la degradación del lenguaje".

GEORge ORWELL.

En una época atravesada por tremendas contradicciones, cuando el hierro de madera es moneda corriente en los círculos políticos y la ambigüedad impera en la comunicación humana, el Decreto-ley, un híbrido con cuerpo de decreto y alma de ley -al decir de CARNELUTT1-, el Bibí Andersen de las normas con rango de ley, ha encontrado perfecto acomodo ecológico.

En otro tiempo, en España, por más que fuese irrelevante la forma fenoménica de manifestarse los mandatos gubernamentales del auto-denominado Movimiento Nacional, supuesto el principio de unidad de poder expresamente reconocido, el Decreto-ley era el instrumento habitual del ejecutivo.

La instauración de un régimen constitucional-democrático alentó, sin duda, esperanzas fundadas en un gobierno mediante leyes pre-establecidas, promulgadas, expresión de la voluntad soberana del pueblo, representada en las Cortes, y en un abandono de la tradicional práctica de

* Comunicación presentado en el Seminario organizado por el Departamento de Derecho Constitucional de la UNED durante el curso académico 1984-85. 
los decretos leyes-improvisados y absolutamente arbitrarios. Los constituyentes, conscientes de la necesidad de dotar de competencias legisladoras al órgano ejecutivo en el marco de un Estado social, reconocieron ciertamente, como excepción al principio general, la facultad gubernamental de dictar normas con rango de ley, pero la sometieron a serias restricciones. Posiblemente, compartían el criterio de MONTESQUIEU, quien consideraba los decretos y edictos "une mauvaise sorte de legislation".

\section{¿Qué ha ocurrido desde entonces?}

La materia incluida en el ámbito de las disposiciones normativas del Gobierno con rango de Ley es muy amplia. Comprende los decretos legislativos, su concepto, vertientes, limites constitucionales de la habilitación al Gobierno para producir este tipo de disposiciones y control de las mismas por los Tribunales ordinarios y por el Tribunal Constitucional. Comprende, asimismo, los decretos-leyes, su naturaleza, ámbito, presupuesto, limitaciones, control en sede parlamentaria y por el Tribunal Constitucional y, en relación con esto último, el problema de la desnaturalización del Decreto-ley y su utilización abusiva e indiscriminada.

De todo ese complejo, me preocupa la cuestión del control y, dentro de ella, la más específica del control de los decretos-leyes ejercido por el Tribunal Constitucional. Las razones son evidentes: de una parte, un hecho histórico, la polémica suscitada por la expropiación mediante Decreto-ley de las acciones del grupo RUMASA y por el fallo recaído en la subsiguiente litis constitucional; de otra, la peculiar exégesis que el Tribunal Constitucional viene realizando de la figura del Decreto-ley, que, como intentaré demostrar, está abocando a una libertad de uso de tal medida cuando menos alarmante, no tanto por lo que formalmente supone para el principio de la división de poderes, como por lo que representa de fisura en los mismos fundamentos del orden jurídico constitucional y, en definitiva, de riesgo cierto para los derechos y libertades.

Pero antes de entrar en el análisis concreto del control constitucional, importa señalar algunos datos que ilustran por sí solos la inequívoca tendencia mostrada por el Gobierno en este campo a partir, lógicamente, de la entrada en vigor de la Constitución actualmente vigente:

- Desde el mes de diciembre de 1978 hasta principios de septiembre de 1984 se dictaron un total de ciento un decretosleyes. Número que resulta difícilmente conciliable, no ya con la realidad sino con la mera posibilidad de que se hayan producido otras tantas situaciones de extraordinaria y urgente necesidad.

- Prácticamente todos los decretos-leyes fueron convalidados por el Congreso, hecho que demuestra la inutilidad -la calificación 
no es excesiva - del control parlamentario en el contexto de un régimen como el nuestro. (Un hipotético Gobierno minoritario no podría recurrir a dicho instrumento normativo porque no conseguiría que se convalidara en la sede parlamentaria, pero ¿acaso podría siquiera gobernar?) Este hecho, además, me exime, dada la falta de interés, de intentar el estudio del citado control.

- Un último apunte introductor relevante: entre el 21 de septiembre de 1979 y el 9 de febrero de 1983, los Gobiernos de UCD y del PSOE dictaron diez decretos-leyes de contenido tributario; diez excepciones, por tanto, al principio de legalidad tributaria, o principio de la auto-imposición.

En España, el Decreto-ley es una norma de carácter provisional, que posee rango de Ley, dictada por el Gobierno en el supuesto de extraordinaria y urgente necesidad. "Se configura, en palabras del Tribunal Constitucional, como una excepción al procedimiento ordinario de elaboración de las leyes, y, en consecuencia, está sometida en cuanto a su ejercicio a la necesaria concurrencia de determinados requisitos que lo legitiman".

Esos requisitos se concretan -en el momento inmediatamente anterior a la decisión gubernamental- en la existencia de una situación de extraordinaria y urgente necesidad. La expresa prohibición constitucional de que los decretos-leyes afecten al ordenamiento de las instituciones básicas del Estado, a los derechos, deberes y libertades de los ciudadanos regulados en el Título $\mathrm{I}$, al régimen de las Comunidades Autónomas y al derecho electoral general es, en realidad, un límite, y no un requisito, de la facultad legislativa del Gobierno ejercitada en la forma de Decreto-ley.

¿Cuál ha sido hasta el presente la posición del Tribunal Constitucial al enjuiciar la concurrencia de aquel requisito? Hay que indicar en este punto que el Tribunal Constitucional es el competente para comprobar si la adopción de la medida en cuestión está o no justificada, entrando a valorar si la definición realizada por el Gobierno de la situación de extraordinaria y urgente necesidad fundamenta debidamente la decisión y si existe "una conexión de sentido entre la situación definida y las medidas que en el Decreto-ley se adoptan". Naturalmente, el Tribunal Constitucional debe resolver - según él mismo reconoce- en base a criterios estrictamente jurídico-constitucionales.

Pues bien, la orientación seguida por el Tribunal Constitucional no puede calificarse de satisfactoria. Veamos las razones que apoyan esta opinión: 
- En la sentencia de 31 de mayo de 1982 que resolvía la impugnación del R. D-L. 10/81 de 19 de junio sobre inspección y recaudación de la Seguridad Social, el problema central del enjuiciamiento de la causa habilitante fue despachada, en su fundamento jurídico 4, en los siguientes términos: «hecha una valoración en su conjunto de todos aquellos factores que hayan aconsejado al Gobierno dictar el R.D-L., no puede afirmarse que no concurra el presupuesto de hecho habilitante que determina el artículo 86, número 1 de la C.E." ¿Cabe considerar tal aserto como demostración de algo? ¿En qué consiste el razonamiento que lleva a la evidencia concluyente del T. C.? Acaso ¿no podría afirmarse exactamente lo contrario partiendo de la misma evaluación factorial global?

- En la sentencia de 4 de febrero de 1983, dimanante de las cuestiones de inconstitucionalidad promovidas en relación con la disposición transitoria segunda, letra b) del R. D-L. de 20 de julio de 1983, sobre medidas urgentes de financiación de las haciendas locales, la capacidad argumental del T. C. alcanza cotas insospechadas en el ámbito del paralogismo.

«Nuestra Constitución - señala la sentencia en el fundamento número 5- ha adoptado una solución flexible y matizada respecto del fenómeno del D-L., que, por una parte, no lleva a su completa proscripción en aras del mantenimiento de una rígida separación de poderes, ni se limita a permitirlo en forma totalmente excepcional en situaciones de necesidad absoluta, entendiendo por tales aquellas en que puede exisitir un peligro inminente para el orden constitucional (...)». iPlaudite cives! Afirmar que la $\mathrm{C}$. reconoce los D-L., pero no como instrumentos para afrontar situaciones peligrosas para el orden constitucional es del todo superfluo porque es obvio; pero el T. C. se sive de esa evidencia para introducir, de paso, algunos elementos destinados a condicionar la actitud de los recurrentes, en el sentido de inducirles a que admitan sub colore iuris la lógica del razonamiento en que se fundamenta el fallo, y también para comenzar a pergeñar una paradójica teoría en torno al presupuesto de hecho habilitante que, como veremos, conduce realmente a un total arbitrio gubernamental para habilitar el presupuesto de hecho.

No se entiende muy bien, en principio, lo de la «solución flexible» adoptada por la C. respecto del D-L.; más bien parece que la $\mathrm{C}$. lo que ha buscado es establecer «un cauce restrictivo para la utilización del D-L. que debería ser escrupulosamente respetado" (I. ASTARLOA). Si algo quedó claro en la mente de los redactores durante el proceso constituyente fue el 
propósito de abandonar para siempre la práctica manipuladora de las normas y la necesidad de recuperar la confianza en el sistema jurídico; mal se concilia con esa finalidad una interpretación del estilo de la preconizada.

Tampoco debería haber sido traida a colación la «rígida" separación de poderes (por lo que tiene de simplificación deformadora abstraida de la realidad de la dinámica política, impensable en el contexto de un régimen parlamentario, de colaboración de poderes), si no fuera porque la preterintencionalidad del supremo intérprete constitucional apunta hacia una supuesta disfunción derivada de aquella separación, para justificar en última instancia un amplísimo margen de actuación del D-L.

La preconstitución del argumento favorable a una exégesis claramente liberadora de las trabas establecidas en la Magna Carta a ese instrumento normativo culmina en el párrafo transcrito con una alusión a las «situaciones de necesidad absoluta, o de peligro inminente para el orden constitucional». La equiparación o asimilación de ambas situaciones es gratuita y parte de una base más que discutible, habida cuenta de que el concepto de necesidad absoluta brilla por su ausencia en el texto constitucional y en la Ley orgánica reguladora de los estados de alarma, excepción y sitio. Pero el T. C. recurre a esa idea extraconstitucional y la subsume en los supuestos de "peligro grave para el sistema constitucional o para el orden público", para, a renglón seguido, contrastarla con la denominada «necesidad relativa"... justificadora de los decretos-leyes. La sentencia adopta así - poniendo un mojón más en el proceso de trasplante de criterios foráneos - la línea del hermeneuta italiano ESPÓSITO. Lo sorprendente, en este préstamo interesado, es que el Tribunal, con ese prurito por incorporar a nuestro acervo jurídico-constitucional la experiencia germano-italiana, haya omitido referir que la apreciación por la doctrina italiana de las necesidades absolutas y relativas trae su causa de que en ese país - según leemos en el espléndido estudio de I. ASTARLOA-, la misma doctrina incluye unánimemente el Decreto-ley entre las Ordenanzas de necesidad; razón por la cual resulta imperativo arbitrar una diferencia específica. No ocurre así en España, donde "con la Constitución en la mano, bien podemos distinguir entre necesidades que ponen en peligro la vida misma del Estado (art. 116) y aquellas urgencias menos angustiosas y más usuales que justifican el Decreto-ley. Por ello - sigue diciendo I. ASTARLOA- quien sigue aquí literalmente a VILLAR PALASI - el Decreto-ley es extraordinario en su origen, pero se inserta luego en el ordenamiento. En cambio, las medidas adoptadas en virtud de las situaciones previstas en el artículo 116 y en la Ley Orgánica de 1 de junio de 1981 paralizan la eficacia del ordenamiento, incrementando temporalmente la potencia ejecutiva del Gobierno, sin que ello signifique huir del Derecho, sino, antes bien, sustituir la normativa ordinaria por leyes especiales durante el tiempo que dure la grave situación de emergencia." 
La distinta ratio y la distinta índole conferidas por nuestro ordenamiento fundamental a las disposiciones mencionadas (decretos-leyes y normas previstas para afrontar estados de excepción), excluyen, en buena lógica, cualquier relación comparativa entre ambas, tanto si se pretende apuntar analogías _porque no existe semejanza o parentesco-, como si se trata de señalar diferencias - porque responden a presupuestos heterogéneos-. Ello le es, sin embargo, indiferente al Tribunal. A él le basta con establecer una conexión claramente discursiva o dialéctica entre aquellas medidas para conseguir que aflore la expresión "necesidad relativa», cuyo significado connota la ambigüedad precisa para privar de contornos definidos a la figura del presupuesto de hecho habilitante: (...) «la necesidad justificadora de los decretos-leyes (...) hay que entenderla como relativa respecto de situaciones concretas de los objetivos gubernamentales que, por razones difíciles de prever, requieren una acción normativa inmediata (...). (...) Es posible hacer uso del Decreto-ley para dar respuesta a las perspectivas cambiantes de la vida actual (...) en todos aquellos casos en que hay que alcanzar objetivos marcados para la gobernación del país (...).

Una conclusión desalentadora cabe extraer al menos de tal exégesis: frente a la estimable tradición de dotar de contenido a los conceptos jurídicos indeterminados -y la extraordinaria y urgente necesidad puede considerarse uno de ellos-, el Tribunal C., no sólo ha decidido reservar a la discrecionalidad del Gobierno la determinación sin pruebas de la concurrencia de la «necesidad extraordinaria y urgente", sino que ha añadido una indeterminación mayor a ese concepto, convirtiéndolo en un mero juego de palabras: la extraordinaria y urgente necesidad relativa.

Desvirtuar de esa manera el requisito exigido por la proposición normativo-constitucional para recurrir al expediente del Decreto-ley significa, sin duda, abrir la espita a un empleo indiscriminado e ilimitado de esa disposición, con los riegos inherentes a un uso de tal naturaleza para la seguridad jurídica. El campo de referencia indefinido que la idea de «necesidad relativa" implica, deja absolutamente en la nebulosa bajo qué condiciones y cuándo -es de esperar que siempre que convenga al Gobierno de turno- se producirán nuevas decisiones del ejecutivo bajo la forma de Decreto-ley. De momento, sabemos a qué atenernos: el Gobierno, además de contar con la iniciativa legislativa se ha convertido, por obra y gracia del T.C. en cuerpo colegislador.

Los razonamientos argumentativos utilizados en las sentencias citadas, y repetidos en la pronunciada sobre el R. D.-L. 1 2/83 (caso RUMASA), son, a mayor abundamiento, una muestra palpable de un fenómeno grave, paralelo al proceso de concentración de poder. Me refiero a la pérdida creciente de la certeza del Derecho - y de la confianza depositada en el mismo-, consecuencia de la latente y progresiva identificación del Derecho constitucional con las necesidades cotidianas de la política. Y no se tome esta afirmación como apología del legalismo y del formalismo. Es- 
tamos asistiendo, de hecho, a un desbordamiento de los límites del amplio marco constitucional, que se está produciendo, procedimentalmente hablando, mediante un rechazo de los cánones usuales -y bastante racionales por cierto - de la actividad interpretativa.

Trataré de sustentar mi aseveración realizando un cotejo de las alegaciones jurídicas esgrimidas por el T.C. en el contexto que me ocupa, con las reglas interpretativas generalmente aceptadas.

Interpretar, juridicamente hablando, equivale a dotar de significado a una norma; norma recogida en un texto que, comprensiblemente, es enjuiciado de distinta forma según la posición adoptada ante el mismo. Piénsese en las diversas «lecturas" de un precepto susceptible de aplicación en una controversia concreta: el demandante, el demandado, el juez u órgano decisorio, el fiscal, el órgano consultivo que preceptivamente emite un dictamen vinculante o determinante, interpretarán con toda probabilidad la norma aplicable de modo distinto. $Y$, sin embargo, existen, definidas por el uso y por la legislación, unas orientaciones a las que todas las partes implicadas suelen acudir para exponer sus respectivos criterios, pretensiones y resoluciones. Entre esos cánones interpretativos se encuentran la referencia a los antecedentes, la explicación gramatical (semántica y sintáctica) del texto normativo en cuestión y la interdependencia de la norma en el marco de la disposición y, en su caso, del sistema jurídico globalmente considerado. Recientemente, se acostumbra a traer a colación también, como pauta interpretativa coadyuvante en el mejor enjuiciamiento del supuesto litigioso, el conjunto de circunstancias socioeconómicas imperante. En esta línea se inscribe, p. ej., el artículo 3.1. de nuestro Código Civil cuando establece que "las normas se interpretarán según el significado propio de las palabras, en relación con el contexto, los antecedentes históricos y legislativos y la realidad social del tiempo en que han de ser aplicadas, atendiendo fundamentalmente al espíritu y finalidad de aquéllas."

La Constitución, en la medida en que es Derecho y norma -por más que sea la piedra angular y la cúspide, el alfa y el omega del sistema jurídico-, está sujeta a las mismas reglas interpretativas, aunque su explicitación revista una terminología peculiar o, aparentemente, suponga un apartamiento de aquéllas. $Y$ es que la actividad interpretativa, en cuanto atribución de significado y alcance a una norma, no cambia de naturaleza a tenor con la índole o posición jerárquica de dicha norma.

Pues bien, la acción interpretativa del Tribunal Constitucional en materia de decretos-leyes parece hasta el presente haber seguido más las preferencias contingentes del poder politico que las directrices o principios rectores de tal actividad. En las sentencias anteriormente aludidas, p. ej., los antecedentes históricos y legislativos que, en buena lógica, hubieran sido de inexcusable referencia, dada la ruptura con el pasado que 
la introducción del régimen constitucional supuso, han sido omitidas, ignorando - y esto es lo que importa - las cautelas y restricciones con que se acogió la figura del Decreto-ley. Asimismo se ha olvidado el «sentido propio" de las palabras, que no es otro que la significatio vulgaris de las mismas, lo que ha llevado a desvirtuar totalmente el presupuesto de hecho habilitante en aras de una razón de Estado, increíblemente asumida por el supremo intérprete constitucional en contradicción con su propia doctrina: «en un plano -decía en la S. de 8 de abril de 1981- hay que situar las decisiones políticas y el enjuiciamiento político que tales decisiones merezcan y en otro plano distinto la calificación de inconstitucionalidad que tiene que hacerse con criterios estrictamente jurídicos.» "EI control parlamentario de los decretos-leyes -reiteraba en la S. de 31 de mayo 1982- se realiza por el Congreso de los Diputados de acuerdo a criterios tanto de oportunidad política como jurídico-constitucionales (...) EI T.C. conoce (...) y resuelve en base a criterios estrictamente jurídico-constitucionales, cimentados sobre la necesidad de determinar, de un lado, si se han respetado o no los requisitos exigidos en la C. para que el Gobierno pueda ejercitar la potestad normativa excepcional de dictar decretos-leyes y, de otro, si del contenido material de la norma se deriva o no una violación de la C." Basta confrontar estos asertos con los - más arriba expuestos-, realizados en el fund. jur. 5 de la S. de 4 febrero 1983, para evidenciar el contrasentido existente entre ambos.

Continuando con el paralelismo que vengo estableciendo entre las pautas de la interpretación jurídica y las adoptadas por el Tribunal Constitucional, la operación de inserción del precepto contemplado en el artículo 86.1 en el conjunto constitucional lo que llama interpretatio ex complexu - sistemática, que deriva del principio de la unidad de la Constitución (Einheit der Verfassung), no ha conducido a los juzgadores a delimitar con precisión el contenido de la potestad conferida al Gobierno desde la perspectiva de la totalidad constitucional. Antes al contrario, las pomposas alusiones al monopolio legislativo de las Cortes Generales como órgano representativo del pueblo español, a la primicia de la ley como expresión de la voluntad popular soberana y a la excepcionalidad de aquella facultad gubernamental, todas ellas trasunto de la concepción democrático-liberal del poder político, no han servido más que para vaciar absolutamente de contenido el régimen jurídico del Decreto-ley. Si de facto se permite que el Gobierno invoque discrecionalmente, sin justificación razonable, la situación de extraordinaria y urgente necesidad, invirtiendo la carga de la prueba que se desplaza al recurrente; si la oportunidad y la conveniencia reemplazan la inevitabilidad como causa de la decisión política que se encarna en la forma de Decreto-ley, el arbitrio, la libre voluntad de los detentadores del poder, se erige en el requisito único determinante de la medida. Evidentemente, tal situación contradice la misma noción del Estado de Derecho y supone una quiebra del edificio constitucional. En fin, ni siauiera el recurso al parámetro de la realidad social $\longrightarrow$ de las ideas sociales predominantes- puede servir para sustentar mínimamente la inter- 
pretación del Tribunal Constitucional. Sí sería útil, en cambio, para apoyar la opinión contraria.

Con todo, el peso de los argumentos choca frontal e infructuosamente contra la realidad. Como es sabido, el Tribunal Constitucional, en su sentencia 111/83, de 2 de diciembre - que declaraba la constitucionalidad del Decreto-ley de expropiación del grupo RUMASA-, reiteró prácticamente la totalidad de su doctrina anterior, que aqui he pretendido refutar. $\mathrm{El}$ análisis de esa sentencia tiene, sin embargo, un interés extraordinario, no sólo por lo que supone en materia de ratificación de enjuiciamientos previos sobre el presupuesto de hecho habilitante, sino, sobre todo, por lo que implica de ruptura de los límites del Decreto-ley. No voy, empero, a criticar aquella decisión, porque esa tarea ya ha sido realizada brillantemente por profesores unversitarios no constitucionalistas. Tan sólo me limitaré a decir que, por lo que respecta a los decretos-leyes, la función realizada por el Tribunal Constitucional hasta este momento se ha apartado de la actividad jurisprudencial para insertarse en un ámbito extraño al rigor, la precisión, la sistemática y la seguridad jurídica y, en todo caso, muy alejado de las intenciones de los constituyentes y peligroso para los gobernados. 